\begin{tabular}{|c|l|}
\hline Title & Reversal learning and generalization in the common marmosets (Callithrix jacchus) \\
\hline Sub Title & \\
\hline Author & $\begin{array}{l}\text { 山崎, 由美子(Yamazaki, Yumiko) } \\
\text { 斉木, 正門(Saiki, Masakado) } \\
\text { 稲田, 正幸(Inada, Masayuki) } \\
\text { 渡辺, 茂(Watanabe, Shigeru) } \\
\text { 入來, 篤史(Iriki, Atsushi) }\end{array}$ \\
\hline Publisher & $\begin{array}{l}\text { Centre for Advanced Research on Logic and Sensibility The Global Centers of Excellence Program, } \\
\text { Keio University }\end{array}$ \\
\hline Publication year & 2012 \\
\hline Jtitle & CARLS series of advanced study of logic and sensibility Vol.5, (2011. ),p.29-41 \\
\hline JaLC DOI & \\
\hline Abstract & I. Study of Logic and Sensibility \\
\hline Notes & Part 1: Brain and Evolution \\
\hline Genre & Research Paper \\
\hline URL & $\begin{array}{l}\text { https://koara.lib.keio.ac.jp/xoonips/modules/xoonips/detail.php?koara_id=KO12002001-2012022 } \\
\text { 4-0029 }\end{array}$ \\
\hline
\end{tabular}

慶應義塾大学学術情報リポジトリ(KOARA)に掲載されているコンテンツの著作権は、それぞれの著作者、学会または出版社/発行者に帰属し、その権利は著作権法によって 保護されています。引用にあたっては、著作権法を遵守してご利用ください。

The copyrights of content available on the KeiO Associated Repository of Academic resources (KOARA) belong to the respective authors, academic societies, or publishers/issuers, and these rights are protected by the Japanese Copyright Act. When quoting the content, please follow the Japanese copyright act. 


\title{
Reversal Learning and Generalization in the Common Marmosets (Callithrix jacchus)
}

\author{
Yumiko Yamazaki ${ }^{1,2,4}$, Masakado Saiki, \\ Masayuki Inada, Shigeru Watanabe ${ }^{1,2,3}$, \\ and Atsushi Iriki ${ }^{4}$
}

${ }^{\prime}$ The Graduate School of Human Relations, Keio University

${ }^{2}$ Centre for Advanced Research of Logic and Sensibility, Keio University

${ }^{3}$ Department of Psychology, Keio University

${ }^{4}$ Laboratory for Symbolic Cognitive Development, RIKEN

Brain Science Institute

\section{Introduction}

Sensitivity to reinforcement, or reward sensitivity, is one of the most basic and important behavioural properties for any animals to survive. It enables us to detect the change in the current condition and to adapt to the new environment appropriately. It always requires animals to attend to a set of stimulus which is potentially relevant to the reinforcement, by ignoring the other stimuli which exist simultaneously. The sensitivity of reinforcement is often related to the cognitive rigidity which is evident in patients with such as Parkinson's disease (Cools et al. 2007). Reward sensitivity is known to require intact brain function especially in orbitofrontal cortex (see Roberts, 2006 for a review).

Reversal learning has been widely used to assess the reward sensitivity in both humans and nonhuman animals (e.g., Cools et al. 2007; Roberts et al. 1988). In this task the subjects have to attend to the relevant stimulus dimension (e.g., size, color, and shape of the stimuli) for reward, and then to learn the specific stimulus-reward associations within that dimension. Because of the procedure requiring the subjects to switch their choices re- 
peatedly after mastering a task, successful performance could not be achieved by subjects with high cognitive rigidity due to some neurological diseases (Roberts et al. 1992).

Except for evaluating the sensitivity of reinforcement and cognitive rigidity, the reversal learning task can be also used to examine animals' categorical ability. For example, one study (Vaughan, 1988) used a set of visual stimuli which did not share any definable characteristics on any stimulus dimension. Then the stimuli were arbitrarily divided into two classes and the pigeons were trained to respond to the stimuli which belonged to either of the sets only on the basis of the consequence of their choices. The experimenter reversed the contingency of the stimulus sets repeatedly, and proved that the pigeons could form functionally equivalent stimulus sets. In addition, using similar reversal procedures, pigeons were proved to be capable of discrimination based on the natural concept such as tree (Herrnstein, 1979), water (Herrnstein, Loveland, \& Cable, 1976), and people (e.g., Herrnstein \& Loveland, 1964; Yamazaki et al. 2007). Thus, the repeated reversal procedure has been used in many studies as one of the convenient and suitable procedures to examine animals' higher-order discriminative abilities.

Recently, the common marmosets (Callithrix jacchus) have been used for researches which aim to uncover the anatomical, behavioral, and neural aspects of the primate evolution (Yamazaki \& Watanabe, 2009 for a review). Connection pattern of frontal regions of this animal is similar to that of macaques (Roberts et al. 2007). Together with the recent successful generation of germline transmission of transgenic marmoset, which is the first report in nonhuman primates, this animal has been expected to be a novel biomedical model to find the biomarkers of human diseases including neurological ones showing cognitive deficiencies (Sasaki et al. 2009). Although there have been increasing number of studies examining the cognitive abilities of this animal (e.g., Yamazaki et al. 2011a, b), it is necessary to have data on basic cognitive abilities such as visual discrimination and its generalization, using procedures which are reliable and easily applicable to them.

In this study, we examined the learning ability and sensitivity of reinforcement in common marmosets by using repeated reversal procedure of visual discrimination tasks. We used the operant chambers installed with the touch-sensitive monitors. After confirming that they could show facilitation 
of learning in the course of the repeated reversals, we tested their generalization ability using novel shapes. This procedure enabled us to examine their conceptual ability based on the relative sizes of given combination of the stimuli, which has been studied as "transposition" in various animals, including rats (Lawrence \& Derivera, 1954), pigeons (Lazareva, Miner,Wasserman, \& Young, 2008), bats (von Helversen, 2004), sea lions (Schusterman, \& Krieger, 1986) and squirrel monkeys (Anderson, Awazu, $\&$ Fujita, 2004). In the transposition test, "stimuli of different absolute value but having the same objective relation to one another" (Spence, 1937) are employed to see animals' ability to understand the situation not on the basis of the absolute value of the learned stimuli, but on the basis of the structure of the task.

\section{Method}

\section{Subjects}

Four adult common marmosets (Subject 1M, 2F, K2F, and 4F), weighing approximately $330 \mathrm{~g}$ to $470 \mathrm{~g}$, were used in the experiments. The animals were laboratory-born, and their ages ranged from $3 y$ to $4 \mathrm{y}$ at the beginning of the study. Subjects $1 \mathrm{M}$ (male) and $2 \mathrm{~F}$ (female) were raised by human caretakers of the breeding company. The others (females) were raised by their parents at RIKEN Brain Science Institute in Wako (hereafter referred to as RIKEN). All animals were housed individually in a breeding room on a 12-hour light-dark cycle. The temperature and humidity in the breeding room were kept, on average, at $28^{\circ} \mathrm{C}$ and $50 \%$, respectively. Testing sessions were always conducted a few hours before daily feeding. The animals were fed regularly, and water was freely available in their cages.

This study complied with the current laws of Japan, including the Act on Welfare and Management of Animals. All experimental procedures and handling methods were performed in accordance with the "Guidelines for Conducting Animal Experiments" of RIKEN, where the experiments were conducted. The experiments were approved by the Animal Experiment Committee at RIKEN. 


\section{Apparatus}

The custom-made experimental chamber was 42 (h) x 34 (w) x 35 (d) cm and was made of stainless steel. The touch-sensitive monitor (TSD-ST173C, Mitsubishi) was located $15 \mathrm{~mm}$ apart from the front panel of the cage. The front panel had an aperture with vertical rods through which the animals could extend their arms and touch on the screen by their hands. The liquid sweetened by brown sugar syrup was delivered when the liquid dispenser was operated as a reinforcer. The reinforcement was signaled by presentation of the pure tone $(1000 \mathrm{~Hz})$ from a speaker located behind the touch monitor and the lightning of the feeder lamp just above the dispenser for 4 seconds. The amount of delivery of the sweetened liquid was about 0.2 to $0.3 \mathrm{ml}$ per one operation. There was a small lamp on the ceiling of the chamber, and it illuminated during each trial. The experimental program was written in the computer language (Delphi) run on a PC (Hp).

\section{Stimuli}

The experimental stimuli were white circles and squares with different sizes presented on the touch-sensitive monitor. There were small (S, 25 pixels in diameter), middle (M, 49 pixels), and large (L, 81 pixels) sized stimuli. The visual angles of these stimuli at the point $50 \mathrm{~mm}$ apart from the surface of the monitor were 6.9, 13.7, and 22.6 degrees, respectively. For the trial initiation stimulus, a distorted picture of a marmoset in black and white (153 x 153 pixels, 43.6 degree of visual angle) was used. Circles and squares with different sizes were used for the subject $1 \mathrm{M}$ and $2 \mathrm{~F}$, whereas squares were used for the subject $\mathrm{K} 2 \mathrm{~F}$ and $4 \mathrm{~F}$. All stimuli were presented on the green background.

For the test of shape generalization, five visual stimuli with different shapes (pentagon, cross, L_shape, star, and triangle) were generated by a PC paint software. The sizes of these stimuli were matched to the baseline stimulus pairs, so 15 stimuli (small, middle, and large ones in each shape) were generated in total.

\section{Procedure}

Pretraining. After the subjects were fully habituated to the experimental 
room and the apparatus, they were trained to touch to the stimulus (circle) on the touch screen using successive approximation technique (i.e. response shaping) until they could respond for more than 60 times without long pause. The position of the stimulus was fixed on the center of the monitor at first, and then was randomized among the 5 positions which were arbitrary defined by the experimental program run by the PC, so that the animals could not expect the position of the stimulus in each trial. When they stably responded to the stimulus presented randomly for 60 times, we added the trial-initiation response to the picture before responding to the training stimulus. They were required to respond once to the picture to initiate the trial, and then the circle stimulus was presented on the monitor. After completion of the one response to the circle stimulus, the reinforcement was delivered. Because some marmosets were fully satiated after being given the reinforcers for more than 40 times on each occasion, we reduced the number of delivery of the reinforcer by setting the probability of reinforcement (0.5-1.0) on each trial, depending on motivation of the individual subjects. That is, if the probability of the reinforcement was set at 0.7 , then the subjects could get sweetened liquid 42 trials on average per session containing 60 trials. For 18 trials without delivery of the sweetened liquid, only the feeder lamp and pure tone was presented for 4 seconds as conditioned reinforcers to signal the correct response and the completion of a given trial. The background of the experimental stimuli was always green except for the period of reinforcement in which the color of the monitor was in black.

Repeated reversal training. The subjects were then trained to touch to the one out of two stimuli until the correct ratio reached to above 0.9 in consecutive 3 daily sessions. The correct response was reinforced by delivery of the sweetened liquid, and the incorrect response was followed by the timeout period for 4 seconds during which the house light was off and the monitor was in black. Inter-trial intervals were set for 5 seconds in average, ranging from 3 to 7 seconds. A daily session was terminated after completion of 60 trials or passage of 60 minutes after starting the session. Positions of the stimulus pair was randomly selected in each trial. The experimental stimuli were the white circles for subject $1 \mathrm{M}$ and $2 \mathrm{~F}$, and they were the white squares for subject $\mathrm{K} 2 \mathrm{~F}$ and $4 \mathrm{~F}$. The stimuli were presented on the green background.

From the next session following the one in which the performance 
reached to the training criterion, the reinforcement contingency of the stimulus pair was reversed. That is, if the correct stimulus which was to be responded in the previous session was $\mathrm{L}$ circle, not $\mathrm{M}$ circle $(\mathrm{L}+\mathrm{M}-)$, then it was changed to $M$ circle in the reversal session without any notice to the animals. If they reached to the criterion in the sessions with the reversed contingencies, then they experienced the next reversal (i.e., now the $\mathrm{L}$ circle is the correct stimulus). These reversals were executed for 4 times before starting the shape generalization and the transposition test sessions described below. The combinations of $\mathrm{S}$ vs. $\mathrm{M}$ and $\mathrm{M}$ vs. $\mathrm{L}$ were trained in each subject, with the randomized order. These training pairs were followed by the shape generalization tests and the transposition tests.

Generalization test to novel shapes. In this generalization tests, we examined whether the subjects could generalize their learning of selecting the larger/smaller one out of two stimuli in the generalization test trials. In the test trials, two stimuli of the same shape (pentagon, cross, L_shape, star, and triangle) with different sizes were presented. These stimuli had never been presented in the training trials, so they were all novel for the subjects. Responses in the test trials were reinforced indifferently: any choice on the test trials was reinforced by delivery of the liquid, and there was no blackout and timeout after the responses. A test session consisted of 40 baseline trials and 20 test trials. The test session was executed twice for each task which was separated by more than one training session with the performance of above 0.9 correct ratio. The size of the test stimuli were matched to that of the baseline training stimuli. If the baseline pairs were $\mathrm{S}+\mathrm{M}-$, with responding to $S$ being reinforced, any shape with the matched size were presented and responding to smaller one was defined as successful generalization.

Transposition tests. The transposition tests were consisted of a combination of the stimuli which were different from that of the baseline trials. That is, if the baseline trials were $\mathrm{M}$ vs. $\mathrm{L}$ with responding to $\mathrm{L}$ being reinforced, the stimulus combination of $\mathrm{S}$ vs. $\mathrm{M}$ was presented in the test trials. In such a test trial, responding to $\mathrm{S}$ was defined as stimulus control by absolute stimulus size (because of avoiding $\mathrm{M}$ as a negative stimulus of the training contingency), whereas responding to $\mathrm{M}$ was considered to be a transposition, because the animal is thought to select on the basis of the relative size of the stimulus set (i.e., $\mathrm{M}$ was larger than the other stimulus). 


\section{Statistics}

We calculated the number of correct responses and the reaction time (latency) of the choice responses. The correct ratio and the reaction time of the test trials was compared with that of the baseline trials in the same test sessions, using the $t$ tests. The test sessions in which the baseline trials had more than $75 \%$ correct ratio were considered to be valid for the further analysis. The reaction times more than $30000 \mathrm{msec}$ were excluded from the analysis. To see the consistency of the generalization performance, we used Spearman's rank correlation, by calculating the rank of the choice ratio in each test stimulus.

\section{Results}

\section{Repeated reversal learning}

All subjects were successfully trained in the simple discrimination and the reversal tasks. Figure 1 shows the scores of the number of sessions to reach

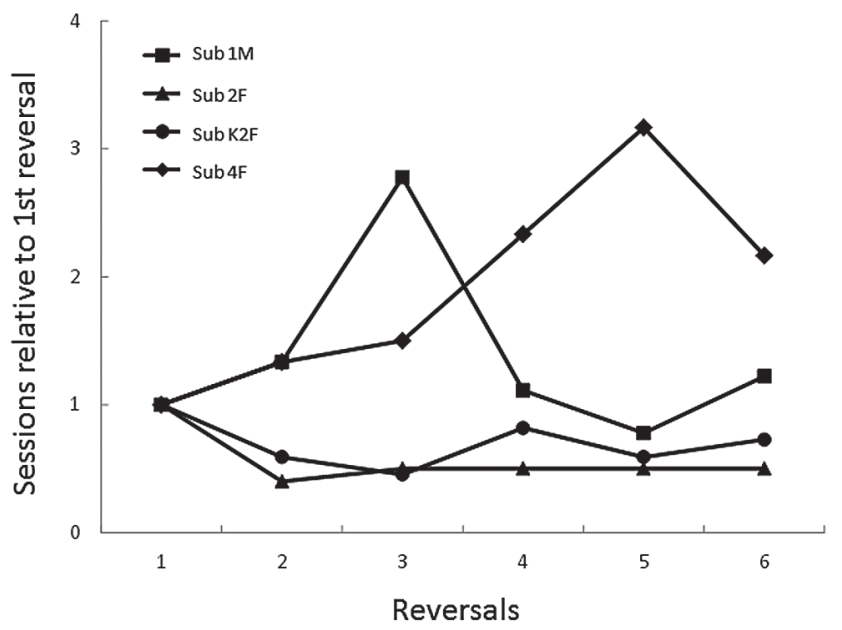

Figure 1. Time course of the performance of the repeated reversals training in the 4 subjects. The performance was evaluated by plotting the value of the number of the required sessions in each reversal, relative to the one of the first reversal. 
to the acquisition criterion of given reversal (i.e., above $90 \%$ correct performance in the consecutive three sessions), which was relative to those in the first reversal session. Subject $2 \mathrm{~F}$ and K2F decreased the scores gradually as the repeated reversals. In the subject $1 \mathrm{M}$, the scores became flat after the third reversal. Subject $4 \mathrm{~F}$ increased the scores up to the fifth reversal for unknown reason.

\section{Generalization test}

The choice preferring the trained relative size in the generalization training is depicted in Figure 2 (left vertical axis), together with the reaction time in msec (right vertical axis). In case that the test in the context of S-M+ discrimination, the choice was above chance (i.e., generalization) in case of the stimulus set of pentagon $(\mathrm{t}(3)=7.348, \mathrm{p}=0.005)$ and triangle $(\mathrm{t}(3)=3.576$, $\mathrm{p}=0.037)$. In the context of $\mathrm{S}+\mathrm{M}$ - discrimination, only the performance in the pentagon trials were above chance $(\mathrm{t}(3)=5.196, \mathrm{p}=0.013)$. In the context of M-L+ discrimination, the successful generalization was observed in the choice to the stimuli of pentagon $(\mathrm{t}(3)=13.000, \mathrm{p}<0.001)$ and triangle $(\mathrm{t}(3)=4.242, \mathrm{p}=0.023)$. There was no above-chance performance in the choice of the $\mathrm{M}+\mathrm{L}-$ discrimination. All the performance in the baseline trials revealed to be above chance $(\mathrm{S}-\mathrm{M}+$ trials, $\mathrm{t}(3)=12.090, \mathrm{p}=0.001$; $\mathrm{S}+\mathrm{M}$ - trials, $\mathrm{t}(3)=20.906, \mathrm{p}<0.001 ; \mathrm{M}-\mathrm{L}+$ trials, $\mathrm{t}(3)=22,192, \mathrm{p}<0.001$; $\mathrm{M}+\mathrm{L}-$ trials, $\mathrm{t}(3)=16.944, \mathrm{p}<0.001)$, thus the trained performance was consistently maintained at high accuracy.

To see the consistency of their generalization performance to the same stimulus shapes with the different combinations of sizes, the Spearman's rank correlation was analyzed depending on the stimulus pairs with same sizes (S-M+ vs. S+M-, M-L+ vs. M+L-) and the stimulus pairs requiring the same relative choices ( $\mathrm{S}-\mathrm{M}+$ vs. $\mathrm{M}-\mathrm{L}+$ (larger positive), $\mathrm{S}+\mathrm{M}-\mathrm{vs} . \mathrm{M}+\mathrm{L}-$ (smaller positive)). When compared on the basis of the same-sized stimulus pairs, Spearman's r was 0.60 (S-M+ vs. S+M-) and 0.88 (M-L+ vs. M+L-), suggesting no significant correlation $(\mathrm{p}>0.10)$. In case of the comparison between the stimulus pairs with same contingencies of relative size, Speaman's $r$ was 0.943 in the larger positive pair (S-M+vs. M-L+) which showed significant correlation $(\mathrm{p}<0.05)$. However, in the smaller positive pair ( $\mathrm{S}+\mathrm{M}-\mathrm{vs}$. $\mathrm{M}+\mathrm{L}-$ ), the $\mathrm{r}$ was 0.428 suggesting no significant correlation. 

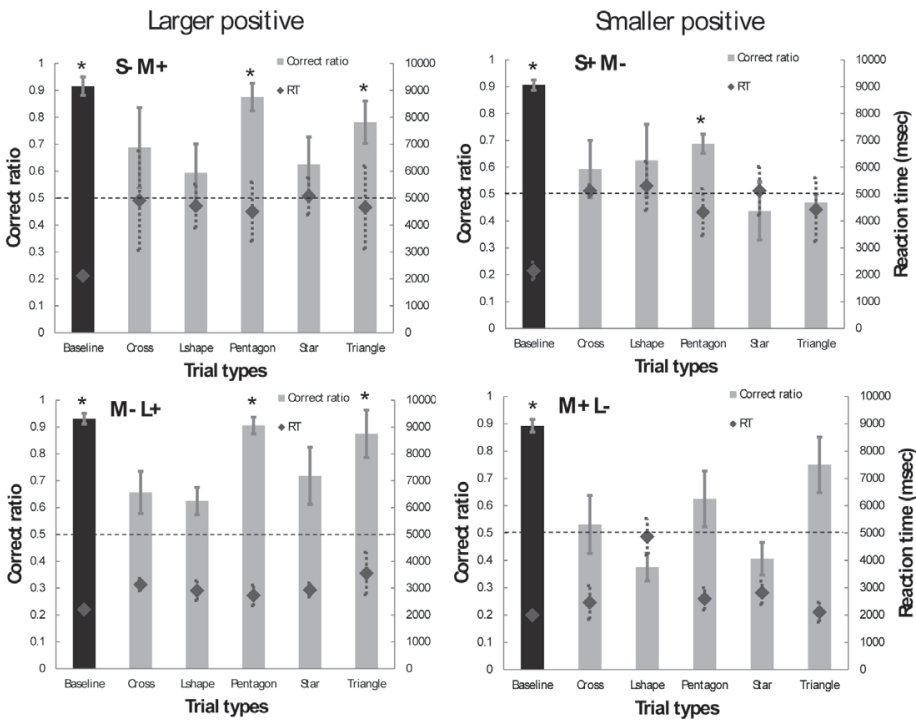

Figure 2. The correct ratio (left y axis) and the reaction times (right y axis) of the baseline and the testing trials of the shape generalization sessions. The left two panels show the results of larger positive combinations (S-M+ and $\mathrm{M}-\mathrm{L}+$ ), whereas the right two panels show the those of smaller positive combinations ( $\mathrm{S}+\mathrm{M}-$ and $\mathrm{M}+\mathrm{L}-)$.

\section{Transposition test}

Figure 3 shows the summary of the results of the transposition tests. The test results in the context of larger positive situation ( $\mathrm{S}-\mathrm{M}+$ and $\mathrm{M}-\mathrm{L}+$ ) is depicted on the left panels, whereas the test results of the context of smaller positive situation ( $\mathrm{S}+\mathrm{M}-$ and $\mathrm{M}+\mathrm{L}-)$ is depicted on the right. The differences between the baseline and test trials in the correct ratio were significant with the stimulus combination of $\mathrm{S}$ and $\mathrm{M}(\mathrm{S}-\mathrm{M}+\mathrm{t} \mathrm{t}(3)=3.43, \mathrm{p}=0.041$, $\mathrm{S}+\mathrm{M}-\mathrm{t}(3)=4.17, \mathrm{p}=0.025)$, but not with the stimulus combinations of $\mathrm{M}$ and L (M-L+: t $(3)=2.29, \mathrm{p}=1.060, \mathrm{M}+\mathrm{L}-\mathrm{t} \mathrm{t}(3)=2.62, \mathrm{p}=0.79)$. But the performance well above the chance was observed only in the two combinations $(\mathrm{S}-\mathrm{M}+\mathrm{t} \mathrm{t}(3)=6.18, \mathrm{p}=0.008, \mathrm{~S}+\mathrm{M}-\mathrm{t}(3)=5.55, \mathrm{p}=0.011)$. 


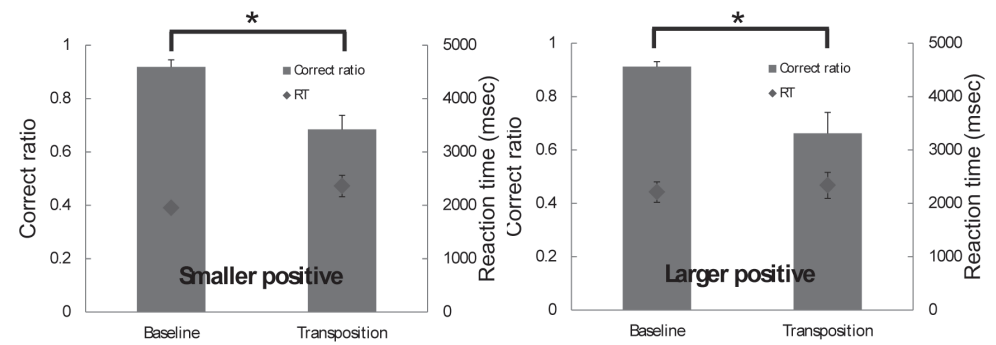

Figure 3. The correct ratio (left y axis) and the reaction times (right y axis) of the baseline and the testing trials of the transposition test sessions. The left two panels show the results of larger positive combinations ( $\mathrm{S}-\mathrm{M}+$ and $\mathrm{M}-\mathrm{L}+$ ), whereas the right two panels show the those of smaller positive combinations ( $\mathrm{S}+\mathrm{M}-$ and $\mathrm{M}+\mathrm{L}-)$.

\section{Discussion}

The present study indicated that the common marmosets successfully learned the visual discrimination tasks and showed facilitation of performance after experiencing the repeated reversals. The facilitation suggested formation of learning set (Harlow, 1949): they learned not only specific stimulus characteristics leading to the reinforcement, but the structure, or requirement of the task to attend to relevant visual stimuli and the switching of the performance once they noticed the change of the environment. Furthermore, the results of the generalization tests indicated the discrimination by concept based on the relative size of the stimulus set. They could base their response even when the stimulus sets were totally novel for them (shape transfer) and had different combinations from those appeared in the training sessions (transposition test).

Transposition can be considered as one of the abstract responding which requires animals to attend not to the specific stimulus but to the combinations or task situation (Spence, 1937). Previous studies examining transposition, however, typically employed the same kind of stimulus with different sizes in the test sessions. Thus, the successful transfer in the shape transfer test in the present study suggested not only the transposition of the relative size, but also the establishment of rule/ concept which was applicable to the novel stimulus dimensions in the common marmosets.

However, the results from the shape generalization and the transposition 
tests were not the one which could be predicted solely on the basis of the relational theory of the transposition (e.g., Lawrence, \& Derivera, 1954). The results were not always consistent to the choice on the basis of the relative size, and were affected by the specific combinations of the stimulus sets. It would have been attributable to their perceptual characteristics in observing the test stimuli. Whether they based their choices on the reinforcement history or relative size of the stimuli was dependent on the stimulus pairs used in the training trials. Perceptual difference of the size between $\mathrm{S}$ and $\mathrm{M}$ stimuli may have been larger than that of the size between $\mathrm{M}$ and $\mathrm{L}$ stimuli (similar finding is found in Lazareva, Miner, Wasserman, \& Young, 2008). Additionally, transposition would have been affected by discriminability of the presented stimulus pairs. All these indicated that the performance of the common marmoset would have not relied solely on the "relation" or "concept" which might have been learned by them during the repeated reversals. Rather, the discrimination based on the difference which can be defined by spatial coordination would have been affected their performance.

In summary, the common marmosets used in the present study showed successful learning of repeated reversals and generalization to the novel stimuli. Their responding was also dependent on the relative size of the stimulus pairs. Further study, however, is needed to clarify the perceptual or conceptual characteristics of this animal to solve the inconsistency of the performance observed in the present study.

\section{Ackowledgement}

The study was supported by the Centre for Advanced Research on Logic and Sensibility, The Global COE Program, at Keio University, Japan, and the Funding Program for World-leading Innovative R\&D on Science and Technology, at RIKEN, Japan.

\section{References}

Anderson, J.R., Awazu, S., \& Fujita, K. (2004). Squirrel monkeys (Saimiri sciureus) choose smaller food arrays: Long-term retention, choice with nonpreferred food, and transposition. Journal of Comparative Psychology, 118, 58-64.

Cools, R., Lewis, S.J., Clark, L., Barker, R.A., \& Robbins, T.W. (2007). L-DOPA disrupts activity in the nucleus accumbens during reversal learning in Parkin- 
son's disease. Neuropsychopharmacology. 32(1), 180-189.

Harlow, H.F. (1949). The formation of learning sets. Psychological Review, 56, $51-65$.

von Helversen, D. (2004). Object classification by echolocation in nectar feeding bats: size-independent generalization of shape. Journal of Comparative Physiology A, 190, 515-521

Herrnstein, R. J. (1979). Acquisition, generalization, and discrimination reversal of a natural concept. Journal of Experimental Psychology: Animal Behavior Processes, 5, 116-129.

Herrnstein, R. J., \& Loveland, D. H. (1964). Complex visual concept in the pigeon. Science, 146, 549-551.

Herrnstein, R. J., Loveland, D. H., \& Cable, C. (1976). Natural concepts in pigeons. Journal of Experimental Psychology: Animal Behavior Processes, 2, 285-311.

Lawrence, D.H. \& Derivera, J. (1954). Evidence for relational transposition. Journal of Comparative Physiological Psychology, 47, 465-71.

Lazareva, O.F., Miner, M., Wasserman, E.A., \& Young, M.E. (2008). Multiple-pair training enhances transposition in pigeons. Learning and Behavior, 36, 17487.

Roberts, A.C. (2006). Primate orbitofrontal cortex and adaptive behaviour. Trends in Cognitive Science, 10, 83-90.

Roberts, A. C., Robbins, T.W., \& Everitt, B.J. (1988). The effects of intradimensional and extradimensional shifts on visual discrimination learning in humans and non-human primates. The Quarterly Journal of Experimental Psychology $B, 40,321-341$.

Roberts, A.C., Robbins, T.W., Everitt, B.J., \& Muir, J.L. (1992). A specific form of cognitive rigidity following excitotoxic lesions of the basal forebrain in marmosets. Neuroscience. 47, 251-264.

Roberts, A. C., Tomic, D. L., Parkinson, C. H., Roeling, T. A., Cutter, D. J., Robbins, T. W., \& Everitt, B.J. (2007). Forebrain connectivity of the prefrontal cortex in the marmoset monkey (Callithrix jacchus): An anterograde and retrograde tract-tracing study. Journal of Comparative Neurology, 502, 86-112.

Sasaki, E., Suemizu, H., Shimada, A., Hanazawa, K., Oiwa, R., Kamioka, M., Tomioka, I., Sotomaru, Y., Hirakawa, R., Eto, T., Shiozawa, S., Maeda, T., Ito, M., Ito, R., Kito, C., Yagihashi, C., Kawai, K., Miyoshi, H., Tanioka, Y., Tamaoki, N., Habu, S., Okano, H., Nomura, T. (2009). Generation of transgenic nonhuman primates with germline transmission. Nature, 459, 523-527.

Schusterman, R.J. \& Krieger, K. (1986). Artificial Language Comprehension and Size Transposition by a California Sea Lion (Zalophus californianus). Journal of Comparative Psychology, 100, 348-355.

Vaughan, W. (1988). Formation of equivalence sets in pigeons. Journal of Experimental Psychology: Animal Behavior Processes, 14, 36-42

Yamazaki, Y., Aust, U., Huber, L., Hausmann, M., \& Güntürkün, O. (2007). Lateralized cognition: Asymmetrical and complementary strategies of pigeons during discrimination of the "human concept". Cognition, 104, 315-344.

Yamazaki, Y. \& Watanabe, S. (2009). Marmosets as a next-generation model of comparative cognition. Japanese Psychological Research, 51, 182-196.

Yamazaki, Y., Echigo, C., Saiki, M., Inada, M., Watanabe, S., \& Iriki, A. (2011a). 
3. Reversal Learning and Generalization in the Common Marmosets (Callithrix jacchus)

Tool-use learning by common marmosets (Callithrix jacchus). Experimental Brain Research, 213, 63-71.

Yamazaki, Y., Iriki, A., \& Watanabe, S. (2011b). Modulation of physical understanding by common marmosets (Callithrix jacchus). Animal Cognition, 14, 175186. 